\title{
Pengaruh Inovasi, Kepercayaan Diri Dan Pengambilan Risiko Terhadap Intensi Berwirausaha Pada Mahasiswa Universitas Tarumanagara
}

\author{
Nathasia dan Rodhiah \\ Program Studi S1 Manajemen Fakultas Ekonomi, Universitas Tarumanagara, Jakarta \\ Email: nathasia.115150304@stu.untar.ac.id
}

\begin{abstract}
The purpose of this study was to determine the effect of innovation, selfconfidence, and risk taking on entrepreneurial intentions. The sample was chosen using nonprobability sampling technique with a number of 100 respondents from Tarumangara University students. The questionnaire was distributed using Google Form and analyzed using the SmartPLS 3.0 program. Individually and as a whole, the results of this study indicate that innovation, self-confidence, and risk taking have a positive effect on entrepreneurial intentions. This means that in entrepreneurial intentions are needed which is innovation, confidence, and risk taking.
\end{abstract}

Keywords: Innovation, Self-confidence, Risk taking and Entrepreneurial Intention.

Abstrak: Tujuan penelitian ini adalah untuk mengetahui pengaruh inovasi, kepercayaan diri, dan pengambilan risiko terhadap intensi berwirausaha. Sampel dipilih menggunakan teknik nonprobability sampling dengan jumlah 100 responden mahasiswa Universitas Tarumangara. Kuesioner disebar menggunakan google form dan dianalisis dengan menggunakan program SmartPLS 3.0. Secara individu dan keseluruhan, hasil penelitian ini menunjukkan bahwa inovasi, kepercayaan diri, dan pengambilan risiko berpengaruh positif terhadap intensi berwirausaha. Artinya dalam intensi berwirausaha dibutuhkan antara lain inovasi, kepercayaan diri, dan pengambilan risiko.

Kata kunci: Inovasi, Kepercayaan Diri, Pengambilan risiko dan Intensi Berwirausaha.

\section{LATAR BELAKANG}

Kegiatan kewirausahaan merupakan hal yang sangat penting bagi perekonomian suatu negara, karena dapat mengurangi jumlah tingkat pengangguran pada suatu negara. Tingkat pertumbuhan ekonomi pada suatu negara tidak lepas dari peran wirausaha. Kewirausahaan dianggap sebagai agen pertumbuhan suatu negara karena dapat membawa perubahan pada ekonomi, teknologi, dan lingkungan organisasi (Gaddam, 2008). Banyak masyarakat terutama mahasiswa yang baru lulus lebih memilih mencari pekerjaan dibandingkan dengan membuka usahanya sendiri (Kusmintarti, Asdani \& Riwajanti, 2017). 
Oleh karena sangat diperlukan berwirausaha agar mampu membuka lapangan pekerjaan yang baru bagi masyarakat luas. Salah satu cara untuk mengatasi masalah tersebut yaitu dengan cara memperluas jumlah wirausaha muda terdidik dalam membuka usaha sendiri (Kusmintarti et al., 2017). Dengan dikembangkan mahasiswa yang terdidik, maka terciptanya wirausaha baru yang dapat mengurangi jumlah pengangguran. (Dickson et al., 2008) menyatakan bahwa pendidikan memaiinkan peran yang penting dalam mengembangkan wirausaha. Belakangan ini, kewirausahaan sebagai profesi dalam pilihan pekerjaan di kalangan mahasiwa dan generasi yang akan datang (Wang, 2011). Dalam hal ini diperlukan adanya dorongan motivasi dan pengembangan terhadap mahasiswa. Peran intensi sangat diperlukan dalam mengerjakan sesuatu, Intensi menjadi seorang wirausaha dipengaruhi oleh faktor. Theory of Planned Behavior menunjukan bahwa intensi diimplikasikan oleh sikap, norma subjektif, dan control perilaku (Ajzen, 1991). Intensi berwirausaha merupakan representasi dari tindakan yang direncanakan untuk melakukan kegiatan kewirausahaan (Tubbs dan Ekeberg, 1991). Wirausaha adalah individu yang berinovasi dan mengkreativitas sesuatu untuk meningkatkan kesejateraan didalam lingkungan bermasyarakat (Raymond, 1995). Inovasi adalah faktor mendorong minat untuk berwirausaha, karena dapat dikatakan mampu menciptakan sesuatu yang belum pernah ada dari sebelumnya atau menginovasi sesuatu yang sudah pernah ada. Individu yang selalu berinovasi dan kreativitas diperlukan self efficacy pada hal yang dilakukan. Percaya diri atau sering disebut self efficacy adalah bagian dari karakteristik psikologis yang dikaitkan seperti internal control dan prospensity to take risks (Ho dan Koh, 1992).

\section{KAJIAN TEORI}

Teori yang mendasar dari penelitian ini adalah Theory of Planned Behavior. Theory of Planned Behavior (TPB) adalah perluasan dari Theory of Reasoned Action (TRA). Ajzen dan Fishbein (1980) mencatat bahwa niat kewirausahaan didasarkan pada individu persepsi tentang kesesuaian karier sebagai pengusaha. Sikap perilaku diartikan sebagai bagaimana sikap individu mempengaruhi niat untuk memulai suatu bisnis (Lee et al., 2011). Dari aspek norma sosial menganalisis dampak dari nilai-nilai budaya dan perbedaan gender pada niat kewirausahaan (Diaz-Garcia dan Jimenez-Moreno, 2010; Shinnar et al., 2012; Siu dan Lo 2013). Dan dari aspek kontrol perilaku mengeksplorasi self-efficacy yang mengukur keterampilan kewirausahaan yang berpengaruh pada niat kewirausahaan (Chen et al., 1998; Zhao et al., 2005).

Rauch et al., (2009), "innovativeness is the predisposition to engage in creativity and experimentation through the introduction of new products/services as well as technology leadership via Rand D in new processes". Menurut pernyataan tersebut menjelaskan bahwa inovasi adalah kecenderungan dalam melibatnya kreativitas dan bereksperimen melalui produk atau jasa dengan teknologi yang baru. Fontana (2011) mendefinisikan bahwa inovasi merupakan keberhasilan dalam hal sosial dan ekonomi karena memperkenalkan cara baru dalam mengubah input menjadi output sehingga menghasilkan perubahan besar dalalm perbandingan antara nilai dan harga menurut persepsi konsumen. Namun Chen (2007) berpendapat bahwa inovasi adalah proses mengubah ide dan mengetahuan menjadi nilai baru melalui berpikir kreatif. Inovatif merupakan elemen penting dari kewirausahaan. 
Vidal Sune dan Lopez Panisello, (2013) menyatakan bahwa kepercayaan diri didefinisikan sebagai keyakinan seseorang terhadap kemampuan individu untuk mengatur dan melaksanakan tugas yang diperlukan untuk mencapai tujuan yang diinginkan dalam hal pencipta bisnis. Selanjutnya Ghufron dan Risnawita (2010: 77) mencatat bahwa secara umum kepercayaan diri adalah keyakinan seseorang tentang kemampuannya untuk mengatasi berbagai macam situasi yang muncul dalam kehidupan. Menurut Turker dan Selcuk, (2009) menganggap bahwa kepercayaan diri secara luas sebagai asset penting yang dimiliki oleh seseorang yang dapat membantu dalam mencapai kesuksesan pribadi. Seperti tingkat pendidikan, dukungan keluarga maupun teman dan faktor lingkungan yang dapat meningkatkan kemandirian.

Suryana (2011) menyatakan bahwa seorang wirausaha harus berani mengambil risiko. Semakin tinggi risiko yang dihadapi maka semakin besar pula kesempatan untuk meraih keuntungan. Pegambikan risiko harus diperhitungkan terlebih dahulu sebelum mengambil keputusan didalam dunia usaha. Karena hasil yang dicapai akan proporsional terhadap risiko yang akan diambil. Disamping itu, Caliendoet Al, (2009) melaporkan bahwa pengambilan risiko bagian dari sifat wirausaha yang menyukai tantangan dan berpengaruh positif pada minat wirausaha. Disisi lain Jain dan Ali (2013) menenutkan bahwa pengambilan risiko yaitu variable psikologis yang mencerminkan kemampuan seseorang untuk mengambil risiko yang sudah diperhitungkan dan tantangan yang dapat dicapai.

Berdasarkan kajian teori yang ada, model penelitian intensi berwirausaha pada mahasiswa disajikan secara visual pada Gambar 1 di bawah ini:

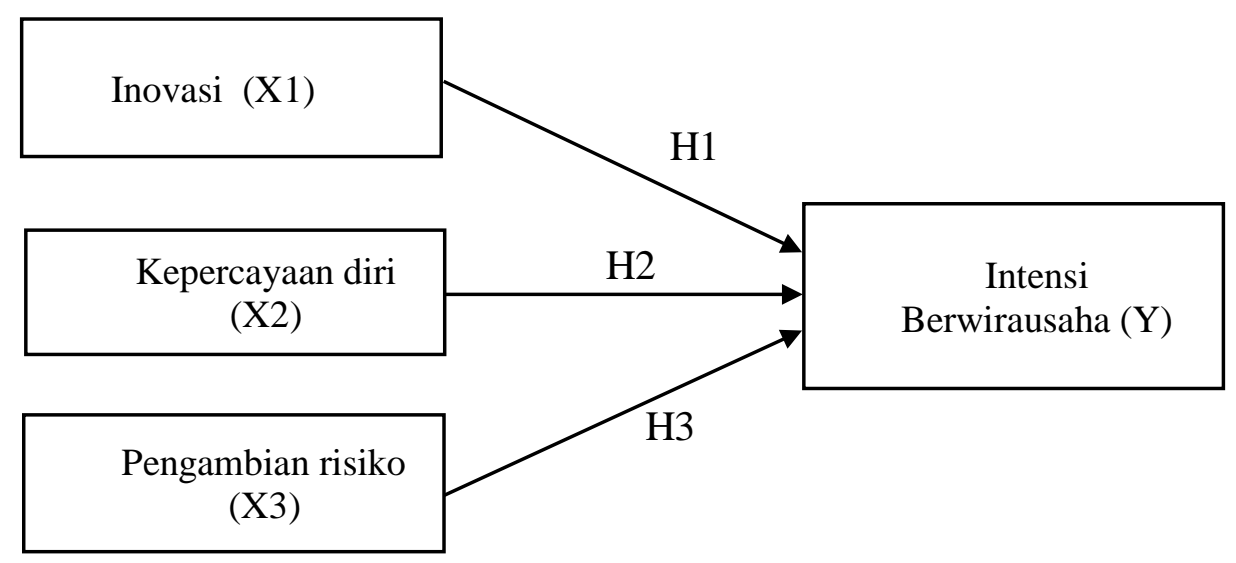

Dari model penelitian di atas, hipotesis yang dihasilkan adalah sebagai berikut:

$\mathrm{H} 1$ : Inovasi memiliki pengaruh yang positif terhadap intensi berwirausaha.

$\mathrm{H} 2$ : Kepercayaan diri memiliki pengaruh yang positif terhadap intensi berwirausaha.

H3: Pengambilan risiko memiliki pengaruh yang positif terhadap intensi berwirausaha.

\section{METODOLOGI}

Penelitian ini merupakan penelitian kuantitatif dengan menggunakan desain penelitian deskriptif karena memuat informasi penelitian sebelumnya dengan variabel yang sama dan hipotesis dalam penelitian ini sudah dapat dirumuskan. Populasi yang dijadikan 
sebagai subjek penelitian ini adalah mahasiswa/i Universitas Tarumangara. Metode pengambilan sampel yang akan digunakan dalam penelitian ini adalah metode nonprobability sampling dengan convenience sampling sebagai teknik pemilihan sampelnya. Convenience sampling mengacu pada kemudahan pengumpulan informasi dari anggota populasi yang bersedia untuk memberikan informasi tersebut (Sekaran dan Bougie 2013). Penelitian ini mengambil sampel sebanyak 100 responden dengan kriteria yaitu merupakan mahasiswa/i Universitas Tarumangara.

Berdasarkan data yang didapat dari 100 (100\%) responden, sebanyak 64 (64\%) responden berjenis kelamin wanita dan sisanya sebanyak $36(36 \%)$ responden berjenis kelamin pria. Kemudian, 100\% berumur 18-23 tahun dan berangkatan 2015-2016. Selain itu, Setiap responden berasal dari berbagai fakultas yang berbeda seperti Fakultas Ekonomi sebanyak 67 orang (67\%), fakultas teknik sebanyak 8, fakultas kedokteran sebanyak 2 orang (2\%0, fakultas senirupa dan desain sebanyak 6 orang $(6 \%)$, fakultas teknologi informasi sebanyak 8 orang (8\%), fakultas hokum sebanyak 1 orang (1\%), fakultas ilmu komuniksasi sebanyak 2 orang (2\%). Penelitian ini menerapkan penggunaan skala Likert sebagai pemberian skor dari setiap indikator dan penyebaran kuesioner dilakukan secara online melalui internet dengan menggunakan google form. Menurut Djaali (2008), skala likert adalah skala yang digunakan untuk mengukur sikap, pendapat, dan persepsi seseorang atau sekelompok orang tentang suatu masalah.

\section{Hasil Uji Statistik}

Hair et al., (2011) menyatakan bahwa uji validitas dapat dilakukan dengan cara mengevaluasi convergent validity dan discriminant validity dalam model penelitian tersebut. Convergent validity diuji dengan menggunakan loading factor dari setiap indikator dan average extracted variance (AVE) dari setiap variabel.

Tabel 1. Hasil Nilai Average Variance Extracted (AVE)

\begin{tabular}{|c|c|}
\hline Variabel & Average Extracted Variance (AVE) \\
\hline Inovasi & 0,612 \\
\hline Kepercayaan Diri & 0,552 \\
\hline Pengambilan Risiko & 0,608 \\
\hline Intensi Berwirausaha & 0,569 \\
\hline
\end{tabular}

Hasil dari AVE menunjukkan nilai sebesar 0,612 untuk variabel inovasi, 0,552 untuk variabel kepercayaan diri, 0,608 untuk variabel pengambilan risiko, dan 0,569 untuk variabel intensi berwirausaha. Hasil ini menunjukkan bahwa setiap variabel di atas telah memenuhi kriteria dengan nilai AVE yang lebih besar dari 0,5 (Hair et al., 2011). Selanjutnya, suatu indikator dinyatakan valid jika mempunyai loading factor di atas 0.6.

Tabel 2. Hasil Nilai Loading Factor

\begin{tabular}{|c|l|c|}
\hline \multicolumn{2}{|c|}{ Indikator } & $\begin{array}{c}\text { Loading } \\
\text { Factor }\end{array}$ \\
\hline IN1 & $\begin{array}{l}\text { Saat orang lain merasa kesulitan , maka saya akan membuka peluang } \\
\text { bisnis. }\end{array}$ & 0,861 \\
\hline
\end{tabular}




\begin{tabular}{|c|c|c|}
\hline IN2 & Saya dapat mengatasi kesulitan dengan cara berpikir dan akal sehat. & 0,812 \\
\hline IN3 & $\begin{array}{l}\text { Saya percaya selalu ada cara baru dan lebih baik dalam melakukan } \\
\text { sesuatu. }\end{array}$ & 0,728 \\
\hline IN4 & $\begin{array}{l}\text { Orang sering meminta saya untuk membantu dalam mencari ide-ide yang } \\
\text { kreatif. }\end{array}$ & 0,720 \\
\hline IN5 & Saya selalu belajar dan ingin tahu terhadap hal-hal yang baru. & 0,782 \\
\hline \multirow[t]{2}{*}{ KD1 } & Saya lebih suka menjalankan sebuah bisnis daripada menjadi karyawan & 0,696 \\
\hline & di perusahaan besar. & \\
\hline KD2 & Saya percaya memiliki bisnis sendiri dapat menarik investor. & 0,632 \\
\hline KD3 & $\begin{array}{l}\text { Saya percaya memiliki bisnis sendiri dapat membantu menjelaskan visi } \\
\text { saya. }\end{array}$ & 0,674 \\
\hline KD4 & $\begin{array}{l}\text { Tidak meragukan kemampuan diri saya sendiri dalam mengatasi kondisi } \\
\text { yang baru. }\end{array}$ & 0,817 \\
\hline KD5 & Percaya dapat mengoperasikan sebuah bisnis dengan sukses. & 0,861 \\
\hline KD6 & $\begin{array}{l}\text { Lebih memilih mengoperasikan bisnis sendiri daripada menjadi } \\
\text { karyawan di sebuah perusahaan ternama. }\end{array}$ & 0,754 \\
\hline PR1 & Saya tidak peduli untung kecil atau besar, selama itu terjamin. & 0,788 \\
\hline PR2 & $\begin{array}{l}\text { Saya bersedia menggambil risiko yang tinggi untuk pengembalian yang } \\
\text { tinggi. }\end{array}$ & 0,823 \\
\hline PR3 & $\begin{array}{l}\text { Saya tidak keberatan bekerja dalam kondisi yang tidak pasti selama ada } \\
\text { yang dapat saya peroleh. }\end{array}$ & 0,761 \\
\hline PR4 & $\begin{array}{l}\text { Saya tidak takut dalam menginveskan uang pada sebuah usaha yang } \\
\text { devidennya sudah terhitung. }\end{array}$ & 0,745 \\
\hline IB1 & Saya siap melakukan apa saja untuk menjadi seorang wirausaha. & 0,777 \\
\hline IB2 & Tujuan saya adalah menjadi seorang wirausaha. & 0,742 \\
\hline IB3 & $\begin{array}{l}\text { Saya akan melakukan segala upaya untuk memulai dan menjalankan } \\
\text { bisnis saya sendiri. }\end{array}$ & 0,740 \\
\hline IB4 & Saya bertekad untuk membangun sebuah perusahaan dimasa depan. & 0,745 \\
\hline IB5 & Saya serius dalam memikirkan jenis perusahaan yang akan dibangun. & 0,769 \\
\hline
\end{tabular}

Sumber: Pengolahan Data SmartPLS 3.0

Berdasarkan hasil dari Tabel 2, telah menunjukkan bahwa seluruh indikator memiliki nilai loading factor di atas 0,6 di mana telah memenuhi syarat convergent validity (Hair et al., 2011), sehingga dapat disimpulkan bahwa semua variabel yang ada dalam penelitian ini telah memenuhi kriteria convergent validity. Dalam pengujian discriminant validity, nilai FornellLarcker yang dimiliki oleh masing-masing variabel pada penelitian ini memenuhi kriteria karena nilai akar kuadrat AVE lebih besar daripada korelasi antar konstruk serta nilai crossloadings masing-masing indikator setiap variabel lebih besar dari nilai cross-loadings variabel lainnya. Berdasarkan hasil analisis convergent validity maupun discriminant validity, maka dapat disimpulkan bahwa variabel dan indikator yang digunakan dalam penelitian ini valid. 
Tabel 3. Hasil Pengujian Reliabilitas

\begin{tabular}{|c|c|c|}
\hline Variabel & Cronbach Alpha's & Composite Realibility \\
\hline Inovasi & 0,840 & 0,887 \\
\hline Kepercayaan diri & 0,812 & 0,869 \\
\hline Pengambilan risiko & 0,835 & 0,880 \\
\hline Intensi Berwirausaha & 0,786 & 0,861 \\
\hline
\end{tabular}

Sumber: Pengolahan Data SmartPLS 3.0

Berdasarkan hasil pengujian reliabilitas pada tabel 3, diketahui bahwa variabel di atas memiliki nilai cronbach's alpha dan composite realibility di atas 0,6. Dengan nilai tersebut, maka dapat disimpulkan bawa data pada penelitian ini reliabel karena memenuhi kriteria dengan hasil yang berada di atas 0,6 (Malhotra, 2012).

Setelah pengujian outer model (validitas dan reliabilitas), pengolahan data variabelvariabel penelitian dilanjutkan pada tahapan pengujian inner model (model struktural) untuk dapat mengetahui kontribusi dari variabel-variabel independen (X) terhadap variabel-variabel dependen $(\mathrm{Y})$. Kriteria pengujian model struktural yang harus dipenuhi pada penelitian ini yaitu nilai koefisien determinasi $\left(\mathrm{R}^{2}\right)$, predictive relevance $\left(\mathrm{Q}^{2}\right)$, dan path coefficients.

Hasil nilai koefisen determinasi $\left(\mathrm{R}^{2}\right)$ pada penelitian ini adalah sebesar 0,838 , berarti $83,8 \%$ dari variabel dependen yaitu intensi berwirausaha dapat dijelaskan oleh variabel independen yang terdapat pada penelitian ini dan sisanya yaitu sebesar 16,2\% dapat dijelaskan oleh variabel-variabel yang tidak termasuk dalam penelitian ini. Berdasarkan kriteria nilai R-Square yang mendekati 1 yang artinya variabel independen memberikan semua informasi yang dibutuhkan untuk memprediksi variasi variabel dependen (Ghozali, 2016). Kemudian, predictive relevance $\left(\mathrm{Q}^{2}\right)$ dengan hasil yang diperoleh sebesar 0,425 $\left(\mathrm{Q}^{2}>0\right)$. Artinya, variabel penjelas intensi berwirausaha yang berupa inovasi, kepercayaan diri, dan pengambilan risiko dapat menunjukkan relevansi prediksi yang memadai atau memprediksi model dengan baik. Pengujian selanjutnya yaitu Goodness of Fit (GoF), dengan hasil sebesar 0,7. Wetzels et al., (2009) menyebutkan bahwa model yang digunakan pada penelitian ini memiliki tingkat kecocokan yang besar.

Tabel 3. Hasil Bootstrapping

\begin{tabular}{|c|c|c|c|}
\hline Variabel & Path Coefficient & t-statistics & p-value \\
\hline $\begin{array}{c}\text { Inovasi } \rightarrow \text { Intensi } \\
\text { Berwirausaha }\end{array}$ & 0,481 & 5,839 & 0,000 \\
\hline $\begin{array}{c}\text { Kepercayaan diri } \rightarrow \\
\text { Intensi Berwirausaha }\end{array}$ & 0,309 & 3,069 & 0,002 \\
\hline $\begin{array}{c}\text { Pengambilan risiko } \rightarrow \\
\text { Intensi Berwirausaha }\end{array}$ & 0,189 & 2,276 & 0,023 \\
\hline
\end{tabular}

Sumber: Pengolahan Data SmartPLS 3.0

Berdasarkan tabel di atas, hasil pengujian bootstrapping (hipotesis) dari seluruh variabel memiliki nilai t-statistics $>1,96$ dan nilai p-values $<0,05$, sehingga dapat dikatakan bahwa hipotesis tidak ditolak dan memiliki arah hubungan yang positif. 
Hasil pengujian hipotesis pertama yang didapatkan untuk variabel inovasi menunjukkan nilai t-statistics sebesar 5,839 dengan p-value sebesar 0,000. Nilai tersebut lebih besar dari cut-off value sebesar 1,96 dan p-value yang lebih kecil dari 0,05 sehingga H1 diterima. Oleh karena itu, dapat disimpulkan bahwa inovasi berpengaruh secara positif terhadap intensi berwirausaha.

Hasil pengujian hipotesis kedua yang didapatkan untuk variabel kepercayaan diri menunjukkan nilai t-statistics sebesar 3,069 dengan p-value sebesar 0,002. Nilai tersebut lebih besar dari cut-off value sebesar 1,96 dan p-value yang lebih kecil dari 0,05 sehingga $\mathrm{H} 2$ diterima. Oleh karena itu, dapat disimpulkan bahwa kepercayaan diri berpengaruh secara positif terhadap intensi berwirausaha.

Hasil pengujian hipotesis ketiga yang didapatkan untuk variabel pengambilan risiko menunjukkan nilai t-statistics sebesar 2,276 dengan p-value sebesar 0,023. Nilai tersebut lebih besar dari cut-off value sebesar 1,96 dan p-value yang lebih kecil dari 0,05 sehingga H3 diterima. Oleh karena itu, dapat disimpulkan bahwa pengambilan risiko berpengaruh secara positif terhadap intensi berwirausaha.

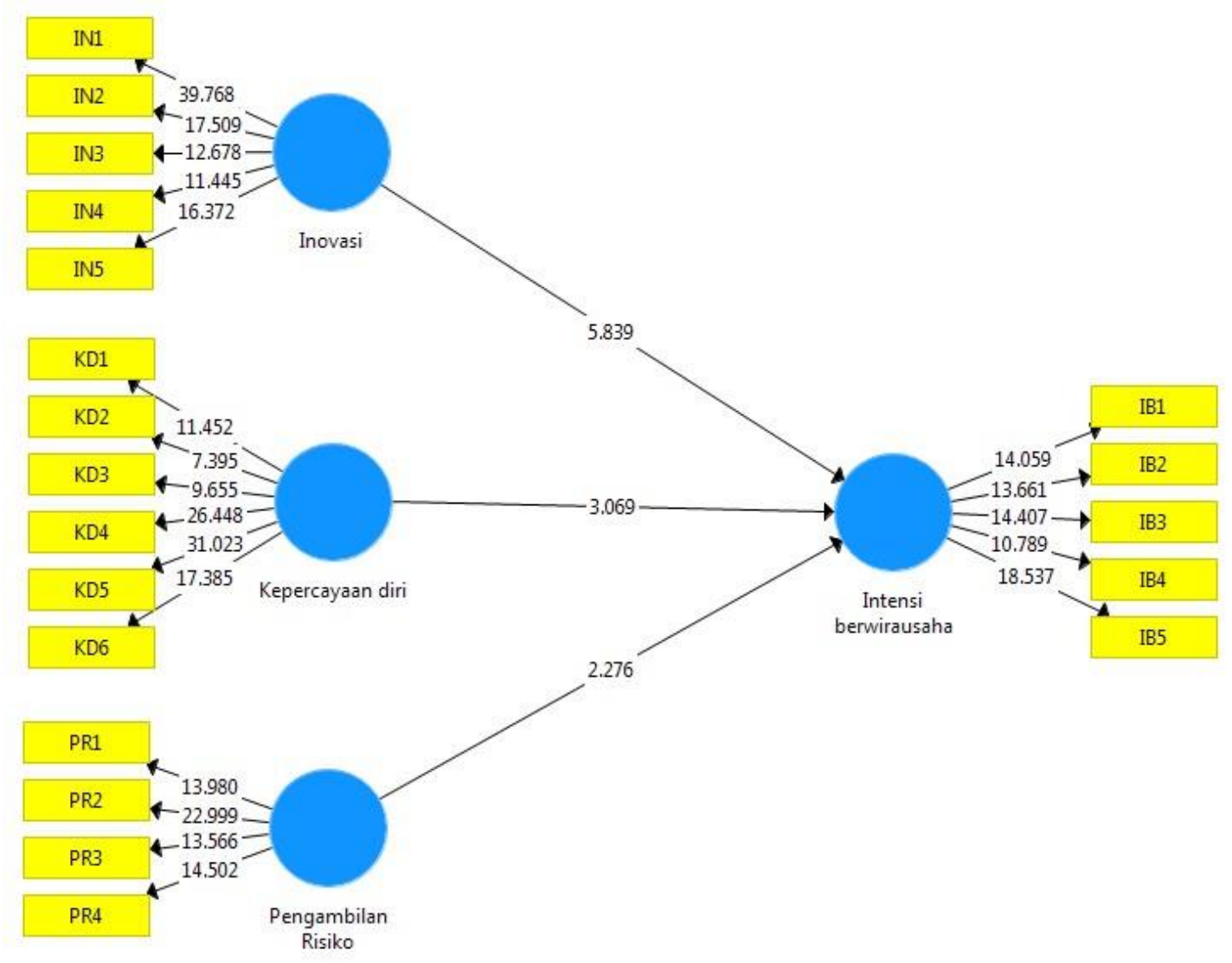

Gambar 2. Hasil Pengujian Bootstrapping

\section{DISKUSI}

Dari analisis data yang telah dilakukan, pengujian pada penelitian ini telah menghasilkan hasil yang sesuai dengan hipotesis. Hasil dari pengujian hipotesis menunjukkan terdapat pengaruh yang positif dari inovasi terhadap intensi berwirausaha pada 
mahasiswa Universitas Tarumanagara. Kemudian, hasil dari pengujian hipotesis dari kepercayaan diri juga menunjukkan pengaruh yang positif terhadap intensi berwirausaha pada mahasiswa Universitas Tarumanagara. Dan hasil pengujian hipotesis menunjukkan bahwa terdapat pengaruh yang positif dari pengambilan risiko terhadap intensi berwirausaha pada mahasiswa Universitas Tarumanagara.

\section{PENUTUP}

Berdasarkan penelitian sebelumnya yang dilakukan oleh Espiritu-Olmus dan SastreCastillo (2015) menemukan adanya hubungan antara ciri kepribadian dan niat kewirausahaan di kalangan mahasiswa di Madrid, Spanyol. Hasil tersebut menunjukan bahwa ciri kepribadian yaitu inovasi, kepercayaan diri, dan pengambilan risiko secara signifikan mempengaruhi intensi berwirausaha. Hal tersebut sejalan dengan hipotesis pertama yaitu inovasi terhadap intensi berwirausaha berpengaruh signifikan. Kemudian penelitian yang dilakukan oleh Sugandini et al., (2018) menemukan bahwa kepercayaan diri memiliki pengaruh terhadap intensi berwirausaha. Pengusaha muda memiliki kepercayaan diri yang tinggi untuk membangun usaha bisnis sendiri, karena mereka yakin dalam kemampuannya untuk beradaptasi dengan lingkungan, teknologi, dan mengantisipasi segala risiko yang mungkin akan terjadi. Hasil penelitian ini juga didukung oleh Ferreira et al., (2012) yang menayatakan bahwa wirausaha memiliki kepercayaan diri yang lebih tinggi dari nonenterpreneur. Hal ini sejalan dengan Hipotesis kedua yaitu kepercayaan diri terhadap intensi berwirausaha berpengaruh signifikan. Selanjutnya penelitian yang dilakukan oleh Uddin dan Bose (2012) yang menemukan bahwa wirausaha menghadapi ketidakpastian dalam membuat keputusan yang membutuhkan perhitungan risiko sebelum mengambil keputusan. Oleh karena itu kecenderungan pengambilan risiko yang secara signifikan berdampak positif terhadap intensi berwirausaha. Hal tersebut sejalan dengan hipotesis ketiga yaitu pengambilan risiko terhadap intensi berwirausah berpengaruh signifikan.

Dalam sebuah penelitian tentunya dapat memiliki beberapa keterbatasan, begitu pula dengan penelitian ini. Keterbatasan dari penelitian ini dikarenakan variabel yang diteliti dalam penelitian ini masih terbilang cukup terbatas yaitu hanya pada tiga variabel independen dan satu variabel dependen, Sehubungan dengan waktu yang relatif singkat dan cakupan wilayah menyebabkan responden dari penelitian ini terbatas dan kurang merepresentasikan mahasiswa Universitas Tarumangara. Selain itu, karena menggunakan kuesioner yang disebar secara online melalui internet, beberapa responden mungkin tidak mewakili populasi dan sampel yang dibutuhkan dalam penelitian ini.

Berdasarkan hasil dan keterbatasan di atas, maka saran yang dapat diberikan untuk penelitian selanjutnya yaitu diharapkan agar jangkauan pengambilan sampel dapat mewakili setiap wilayah yang telah ditentukan dalam penelitian, sehingga setiap respondennya dapat mewakili subjek penelitian dengan tepat. Selain itu, disarankan agar lebih diperbanyak dan ditambahkan variabel-variabel lain di luar variabel yang telah dibahas dalam penelitian ini dan variabel lain yang berpengaruh terhadap intensi berwirausaha. 


\section{DAFTAR PUSTAKA}

Ajzen, I. (1991). The theory of planned behavior. Organizational Behavior and Human Decision Process, 50, 179-211.

Baron, R. A., \& Byrne, D. (2003). Psikologi sosial. Jakarta: Erlangga.

Caliendo, M., Fossen F. M. and Kritikos A. S. (2009) 'Risk Attitudes of Nascent Entrepreneurs-New Evidence from an Experimentally-Validated Survey', Small Business Economics, Vol. 32, No. 2, pp.153-167.

Chen, M. H. (2007). Entrepreneurial leadership and new ventures: creativity on entrepreneurial teams. Creativity and Innovation Management, 16(3), 239-249.

Cohen, Jacob. (1988). Statiscal Power Analysist for the Behavioral Sciences (Ed. 2). Hillsdale: Erlbaum Associates.

Diaz-Garcia, M., and J. Jimenez-Moreno. 2010. "Entrepreneurial Intentions: The Role of Gender." International Entrepreneurship and Management Journal 4(4):467-83.

Espíritu-Olmos, R., \& Sastre-Castillo, M. (2015). Personality traits versus work values:

comparing psychological theories on entrepreneurial intention. Journal Of Business Research, 68(7), 1595-1598.

Fayolle, A., Gailly, B. and Lassas-Clerc, N. (2006), "Assessing the impact of entrepreneurship education programmes: a new methodology", Journal of European Industrial Training, Vol. 30 No. 9, pp. 701-720.

Ferreira, J.J., Raposo, M.L., Rodrigues, R.G., Dinis, A. and Paço, A.D. (2012), “A model of entrepreneurial intention: an application of the psychological and behavioral approaches", Journal of Small Business and Enterprise Development, Vol. 19 No. 3, pp. 424-440.

Fontana, Avanti. 2016, “Innovation or Die : What A Company Was Do".Materi dipresentasikan pada Indonesia Knowledge Forum V-2016 7 Oktober 2016.

Garaika, \& Margahana, H. (2019). Self Efficacy, Self Personality and Self Confidence on Entrepreneurial Intention: Study on Young Enterprises. Journal of Entrepreneurship Education, 2(1).

Gelaidan, H.M., Abdullateef, A.O. (2017). Entrepreneurial intentions of business students in Malaysia: The role of self-confidence, educational and relation support. Journal of Small Business and Enterprise Development, 24(1), 54-67.

Ghozali, I. (2014). Structural Equation Modeling, Metode Alternatif dengan. Partial Least Square (PLS). Edisi 4. Semarang : Badan Penerbit Universitas.

Gurel, E., Altinay, L. and Daniele, R. (2010), “Tourism students' entrepreneurial intentions", Annals of Tourism Research, Vol. 37 No. 3, pp. 646-669.

Hair, J. F., Ringle, C. M., \& Sarstedt, M. (2011). PLS-SEM: Indeed a Silver Bullet. The Journal of Marketing Theory and Practice, 19(2), 139-151.

Ho, T.S. and Koh, H.C. (1992), "Differences in psychological characteristics between entrepreneurially inclined and non-entrepreneurially inclined accounting graduates in Singapore", Entrepreneurship, Innovation and Change: An International Journal, Vol. 1 No. 2, pp. 243-254.

Kusmintarti, A., Asdani, A., \& Riwajanti, N.I. (2017). The relationship between creativity, entrepreneurial attitude and entrepreneurial intention (case study on the students of State Polytechnic Malang). Int. J. Trade and Global Markets, 10(1), 28-36. 
Lee, L., Wong, P. K., Chua, B. L. and Chen, J. (2011), 'Antecedents for entrepreneurial propensity: Findings from Singapore, Hong Kong and Taiwan'.

Luthje, C. \& Franke, N. (2003). The making of an entrepreneur: testing a model of entrepreneurial intent among engineering students at MIT. R\&D Management, 33(2), $135-47$.

Malhotra, N.K. (2015). Essentials of Marketing Research. England: Pearson Education Limited.

Rauch, A., \& Frese, M. (2007). Let's put the person back into entrepreneurship research: A meta-analysiship between business owners'personality traits, business creation, and success. European Journal of Workand Organizational Psychology, 16(4), 353-385. Sekaran, U., \& Bougie, R. (2013). Research Methods for Business (6th ed.). Italy: Printer Trento Srl.

Suryana. 2011. Kewirausahaan Pendoman Praktis: Kiat dan Proses Menuju Sukses. Jakarta: Salemba Empat

Tubbs, M. E., \& Ekeberg, S. E. (1991). The role of intentions in work motivation: Implications for goal-setting theory and research. The Academy of Management Review, 16(1), 180-199.

Turker, D., \& Selcuk, S. S. (2009). 'Which factors affect entrepreneurial intention of university students?'. Journal of European Industrial Training, 33(2), 142-159.

Vidal-Sune, A. and Lopez-Panisello, M. (2013), "Institutional and economic determinants of the perception of opportunities and entrepreneurial intention", Investigaciones Regionales, Vol. 26, pp. 75-96.

Wang, C. K., \& Wong, P.-K. (2004). Entrepreneurial interest of university students in Singapore. Technovation, 24(2), 163-172.

Wetzels, M., Odekerken-Schroder, G., \& Van Oppen, C. (2009). Using PLS path modeling for assessing hierarchical construct models: Guidelines and empirical illustration. MIS Quarterly, 33(1), 177-195. 